\title{
Os transtornos alimentares: causas e tratamento numa visão multidisciplinar
}

\section{The alimentary upset: causes and treatment in a multidiscipline vision}

\author{
Kátia Melek ${ }^{1}$ \\ Ana Claudia C. de Ornelas Maia ${ }^{2}$
}

Artigo

Original

\begin{abstract}
Palavras-chaves:
Resumos

Alimento

O presente artigo tem como objetivos a instrução das pessoas de nossa

Família sociedade sobre a importância dos transtornos alimentares, quanto à conceituação, causas e o tratamento numa visão multidisciplinar. Através de um estudo referenciado em bibliografias atualizadas sobre esses transtornos,

Multidisciplinar bem como o sofrimento das pessoas as quais são acometidas por eles. A participação da família é fundamental no tratamento e na interação com uma equipe de profissionais acerca de possibilidades de conscientização e normalização das alterações psiquiátricas, psicológicas, físicas e nutricionais.
\end{abstract}

\begin{abstract}
The herein presented article has as objective, the instruction of the people of our society on the importance of the alimentary upheavals, comcerning the conceptualization, causes and the treatment in a multidisciplinary vision. The study uses a bibliography approach about these upheavals, as well as the suffering of the people which are compromised by them. The participation of the family is basic for the treatment and the interaction of a team of professionals concerning awareness possibilities and normalization of psychiatric, psychological, physical to meet the foreseen results.
\end{abstract}

Key words:

Aliment

Family

Multidiscipline
Original

Paper

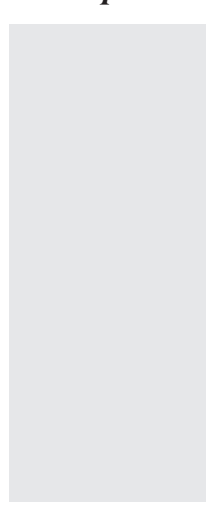

Submetido

em: 28/12/07

Revisado

em: 13/01/08

Aceito para

Publicação

em: 25/03/08

\section{Introdução}

Os transtornos alimentares, na forma como se apresentam atualmente, emergem das pesquisas epidemiológicas como doenças relativamente modernas e predominantemente ocidentais. Assim, as sociedades ocidentais contemporâneas vivem atualmente sob o ideal da magreza e da boa forma física. Este padrão se impõe especialmente para as mulheres, nas quais a aparência física representa uma importante medida de valor pessoal.

Embora a aparência física seja um elemento fundamental da imagem da mulher em diversas épocas e culturas, a extrema magreza nem sempre foi o ideal almejado. Uma passagem rápida pela história da humanidade, revela que a Renascença valorizava mulheres de corpo cheio, em outras décadas o espartilho dava à mulher uma imagem corporal mais adelgaçada, sem ser a dieta o principal meio para conseguir o efeito longilíneo e fino. Atualmente, dietas e exercícios físicos parecem ser o principal meio para modificar o corpo, dando uma falsa noção de que o corpo é infinitamente maleável.

Mudanças sociais foram observadas quando mulheres passaram a ocupar postos de

\footnotetext{
${ }^{1}$ Psicóloga, especialista em transtornos alimentares, pós-graduanda em terapia cognitivo-comportamental nas instituições e na clínica na UNIFOA.

${ }^{2}$ Psicóloga, especialista em terapia cognitivo-comportamental, mestre em sexologia, coordenadora do curso de pós-graduação em terapia
} cognitivo-comportamental nas instituições e na clínica na UNIFOA e professora de psicologia da UNESA. 
trabalho anteriormente ocupados por homens. Juntamente com essas mudanças, o hábito alimentar também foi alterado. Pressões sociais e da mídia associadas a facilidades para se alimentar mal, têm contribuído para o aumento da ocorrência dos transtornos alimentares.

É importante que a família fique atenta ao menor sinal de qualquer dos transtornos alimentares, pois é comum aparecerem na adolescência ou início da vida adulta.

Sendo os transtornos alimentares desenvolvidos a partir de diversos fatores predisponentes (genéticos, biológicos, psicológicos e socioculturais), podem assim trazer vários tipos de danos ao indivíduo. $\mathrm{O}$ isolamento social é percebido na maioria dos casos, porque a baixa auto-estima está presente em muitos deles. Associam o corpo a uma medida de desempenho do indivíduo. Normalmente têm um nível de exigência consigo mesmos muito alto, sendo difícil de ser atingido, levando à frustração e conseqüente ciclo vicioso, reduzindo cada vez mais a autoestima, por não se sentirem capazes de atingir as metas por eles mesmos propostas.

A formação de uma equipe multidisciplinar somada ao apoio da família é de vital importância para o bom desempenho do tratamento.

Neste artigo, os transtornos alimentares são abordados relevando a sua problemática, ou seja, relacionando-os aos problemas físicos, biológicos e emocionais sendo considerado atualmente uma preocupação nacional.

O objetivo principal é relacionar os transtornos alimentares com a imposição da mídia e pressões sociais na busca incessante do ideal de corpo magro. Associar a imagem corporal com o desempenho de vários aspectos da vida (social, profissional, emocional, etc) reforça a necessidade de equipe multidisciplinar para o sucesso do tratamento, aliado à família.

\section{Transtornos Alimentares}

Segundo Rangé (2001), os transtornos alimentares caracterizam-se por sérios distúrbios no comportamento alimentar. Desenvolvem-se a partir de diversos fatores predisponentes (genéticos, biológicos, psicológicos e socioculturais) trazendo vários tipos de danos ao indivíduo. Dentre os Transtornos Alimentares descritos pela psiquiatria, estão a Anorexia Nervosa, a Bulimia Nervosa e a Compulsão Alimentar esta última, muito recente e polêmica. Estudos de suas características particulares ainda estão em fase inicial de desenvolvimento. Sabe-se, portanto, que esta categoria está situada entre a Bulimia Nervosa e a Obesidade Primária (Ballone, s/d).

Os critérios diagnósticos para Anorexia Nervosa que são mais utilizados atualmentesãooriundos do ManualDiagnóstico e Estatístico de Transtornos Mentais -DSM - IV (APA, 1995), como segue:

A. Recusa a manter o peso corporal em um nível igual ou acima do mínimo normal adequado à idade e à altura ou acima deste. Por exemplo, perda de peso levando à manutenção do peso corporal em um nível menor que $85 \%$ do esperado; ou fracasso em ter o ganho de peso esperado durante o período de crescimento, levando a um peso corporal menor do que $85 \%$ do esperado.

B. Medo intenso de ganhar peso ou de se tornar gordo, mesmo com peso inferior ao esperado.

C. Perturbação no modo de vivenciar o peso, tamanho ou forma corporal. Por exemplo, a pessoa reclama que se "sente gorda" ou acredita que uma área do corpo está "muito gorda" mesmo quando obviamente tem peso inferior ao desejável. $\mathrm{O}$ peso o formato corporal exercem influência indevida na auto-avaliação ou há negação da seriedade do baixo peso corrente.

D. Nas mulheres pós-menarca, ocorre amenorréia, isto é, a ausência de pelo menos três ciclos menstruais consecutivos, quando é esperado ocorrer o contrário.

Tipos:

Tipo Restritivo: durante o episódio atual de anorexia nervosa, o indivíduo não se envolveu regularmente em um 
comportamento de comer compulsivamente ou de purgação (isto é, auto-indução de vômito ou uso indevido de laxantes, diuréticos ou enemas).

Tipo Compulsão Periódica/Purgativo: durante o episódio atual de anorexia nervosa, o indivíduo envolveu-se regularmente em um comportamento de comer compulsivamente ou de purgação (isto é, auto-indução de vômito ou uso indevido de laxantes, diuréticos ou enemas)

$\mathrm{Na}$ Anorexia Nervosa, a pessoa passa a viver exclusivamente em função da dieta, apresenta medo intenso de engordar, preferência pela magreza extrema e distorção da imagem corporal, impondo-se limites cada vez mais baixos para a redução de peso. $\mathrm{O}$ comportamento alimentar torna-se secreto e por vezes bizarro. Algumas pacientes chegam a pesar todos os alimentos antes de ingeri-los e em alguns casos, fala-se em orgias alimentares, com ingestão de alimentos outrora "proibidos", alimentos estes, normalmente com grande valor calórico. Atitudes compensatórias podem vir a ocorrer para neutralizar tal efeito: prática excessiva de exercícios, uso de laxantes e diuréticos, indução de vômito. Para conseguir redução de peso, a pessoa pode chegar a fazer jejum quase completo, embora a perda de apetite seja rara (Rangé. B.,2001).

Segundo Nunes et al. (2002), o início da anorexia nervosa ocorre freqüentemente na adolescência, a partir de uma dieta restritiva, e tem como fator desencadeante algum evento significativo (perdas, separações ou outro fator estressante).

Embora não se percebam como portadoras de doença, com o passar do tempo, com todas essas atitudes ritualizadas, tornamse isoladas do meio social e da própria família. Normalmente, "para a família, ela é vista como ótima filha, muito dócil e obediente." (Nunes et al., 2002). Outra característica marcante das anoréxicas é o pensamento dicotômico do tipo "tudo" ou "nada", sem categorias intermediárias, que não se resume apenas no comportamento alimentar, mas em todos os campos da vida. Se não estão em absoluto controle, significa que estão totalmente sem controle.
“Com a evolução da doença, a desnutrição pode chegar num nível grave o suficiente para levar à morte ou causar danos irreversíveis ao organismo. As taxas de letalidade da anorexia nervosa oscilam entre 5 a 20\%". (Nunes, et al., 2002).

Na Bulimia Nervosa, o indivíduo ingere grande quantidade de comida em curto espaço de tempo, quantidade esta visivelmente maior do que a maioria das pessoas ingeririam se comparados ao mesmo período de tempo e situações similares, envolvendo ainda, falta de atenção ao paladar e pouca mastigação. Em geral, esses ataques ocorrem no final do dia ou à noite, momento em que se acham sozinhas, porque esses comportamentos são desenvolvidos às escondidas, embora costumem deixar rastros pela casa como embalagens encontradas na lata do lixo, alimentos que desaparecem da despensa e "ninguém encontra o responsável por isso" (Rangé, 2001).

De acordo com o DSM - IV (APA, 1995), para que se caracterize a Bulimia Nervosa, são seguidos alguns critérios:

A.Episódios de "Binge-eating" recorrentes. Um episódio deste caracteriza-se por:

(1) comer, em um período limitado de tempo, por exemplo, dentre de um período de duas horas), uma quantidade de alimento que é claramente maior do que a maioria das pessoas comeria durante um período de tempo semelhante, em circunstâncias semelhantes.

(2) sentimento de falta de controle sobre o comportamento alimentar durante tais episódios. Isto é: um sentimento de não conseguir parar de comer ou controlar o tipo ou quantidade de alimento.

B. Empenho recorrente em comportamento compensatórios inadequados para prevenir o ganho de peso, tais como: vômitos auto-induzidos; uso inadequado de laxantes, diuréticos, enemas ou outros medicamentos; dieta restritiva; jejum ou exercícios excessivos.

C. Os episódios de "Binge-eating" e comportamentos compensatórios inadequados devem ambos ocorrer, em média, pelo menos duas vezes por semana 
durante três meses.

D. A auto-avaliação é inadequadamente influenciada pelo peso e formato corporal.

E. O distúrbio não ocorre exclusivamente durante episódios de Anorexia Nervosa.

Pacientes bulímicas sepreocupamtanto com o formato corporal quanto as anoréxicas e quando ocorrem os ataques de compulsão alimentar, sentem-se culpadas e fracassadas e o medo de engordar aumenta, fazendo com que imponham um limite de peso para si próprias abaixo do considerado saudável. Pacientes bulímicas que utilizam métodos purgativos apresentam maior grau de insatisfação com o corpo quando comparados ao grupo que utiliza métodos não purgativos (Nunes, 2002). Na busca incessante para emagrecer, as pacientes podem desenvolver um quadro de anorexia nervosa.

A fome costuma ser o principal disparador de um episódio bulímico, uma vez que as bulímicas não suportam a restrição alimentar por um longo período de tempo. Os constantes ataques bulímicos com posterior purgação, vão se tornando mais freqüentes e passam a serem associados a eventos estressantes da vida, tais como solidão, perdas e relacionamentos afetivos. Ainda que sintam culpa e vergonha por essa prática, os ciclos de bulimia e purgações são tidos como relaxantes (Range, 2001). Tal como Nunes et al. (2002) descrevem, com o passar do tempo, se vêem presas no ciclo vicioso bulimia/purgação e suas condutas passam a interferir na vida social e profissional. Não se sentem à vontade em ambientes públicos, por sentirem-se incapazes de controlar o que vão comer e/ou não encontrarem condições para purgarem secretamente. Tal como na Anorexia Nervosa, a Bulimia Nervosa geralmente inicia na adolescência ou no início da vida adulta. A história da bulimia nervosa pode iniciar-se por uma necessidade real ou imaginária de perder peso, decorrente de uma intensa insatisfação com o corpo. Sentimentos de baixa auto-estima correm paralelos à constante insatisfação com a forma corporal, ou seja, a auto-estima depende da eficiência de seus métodos para alcançar o corpo desejado (Nunes et al., 2002).

As semelhanças entre a anorexia nervosa e a bulimia nervosa são grandes, havendo diversos níveis de transição entre eles, como bulímicas com períodos de anorexia e anoréxicas com ataques bulímicos. Segundo Nunes et al. (2002), “as bulímicas conseguem aceitar, na maior parte das vezes, um peso que é mais adequado para sua idade e estatura, ainda que desejem se manter próximas aos limites inferiores dos padrões de normalidade".

A terceira categoria dos transtornos alimentares é o que podemos chamar de Transtorno da Compulsão Alimentar Periódica (TCAP) ou transtorno do comer compulsivo. Essa categoria ainda está em fase de estudos por situar-se entre a Bulimia Nervosa e a Obesidade Primária. Caracteriza-se tal qual a bulimia nervosa no que se refere ao controle alimentar diante de outras pessoas, porém apresentam episódios do comer compulsivo (episódios bulímicos do tipo "bingeeating"), sem posteriores comportamentos compensatórios, como excesso de exercícios, abuso de laxantes, indução ao vômito, dentre outros. Durante esses ataques, os indivíduos costumam ingerir alimentos com grande valor calórico, preferencialmente do grupo dos carboidratos, experimentam a sensação de perda de controle sobre o comportamento alimentar e só param de comer quando sentemse desconfortavelmente cheios. (Range, 2001)

Muito embora nem todos os pacientes que apresentam transtorno do comer compulsivo sejam obesos, grande parte deles evidenciam problemas de controle do peso corporal (Nunes et al., 2002). Ainda que às vezes façam dieta, a grande maioria apresenta obesidade moderada a grave.

Comerdemaispodeparecerinofensivo e normalmente é inofensivo. Eventualmente, comemos mais do que precisamos, sem distinção da fome e da "vontade de comer". Mas, o limite entre o inofensivo e o problemático são tênues, daí a necessidade de padronizar critérios diagnósticos para tal transtorno. De acordo com o DSM - IV (APA, 1995), Apêndice B (esse apêndice é dedicado ao conjunto de eixos sugeridos para estudos adicionais) os critérios diagnósticos para o Transtorno do Comer Compulsivo são:

A. Episódios recorrentes de ataques de comer. Um episódio de ataque de comer é caracterizado por:

(1) Comer num breve período de tempo 
(por exemplo, num período de duas horas) uma quantidade de comida considerada definitivamente maior do que a maioria das pessoas comeria durante um período de tempo similar e em circunstâncias similares.

(2) Uma sensação de falta de controle durante os episódios, isto é, um sentimento de que não pode parar de comer ou controlar o que ou o quanto o indivíduo está comendo.

B. Os episódios de ataque de comer estão associados a pelo menos três (3) ou mais dos seguintes itens:

(1) Comer mais rápido do que o usual.

(2) Comer até se sentir inconfortavelmente "cheio".

(3) Comer grandes quantidades de comida, sem se sentir com fome.

(4) Comer sozinho por se sentir constrangido com a quantidade que está comendo.

(5) Sentir-se decepcionado, deprimido, ou sentindo-se culpado após a superingestão.

C. O ataque de comer provoca um marcante desconforto.

D. Os episódios de ataque de comer ocorrem em média duas (2) vezes por semana durante seis meses.

E. O ataque de comer não está associado com o uso regular e inapropriado de comportamento compensatório (por exemplo, do tipo purgativo, jejuns ou exercício excessivo) e não ocorre exclusivamente durante o curso de anorexia nervosa ou bulimia nervosa.

Pessoas que têm este tipo de transtorno apresentam flutuações de peso de longa data. É o que chamamos de "efeito sanfona", resultado de dietas muito rigorosas e posterior fracasso diante disso. Em geral, isso acontece no final da adolescência, quando as transformações no corpo tornam-se evidentes. Algumas meninas até conseguem alguma redução de peso temporária, mas não resistem à dieta por muito tempo, voltando a engordar, muitas vezes, mais do que o peso inicial. Os padrões de beleza atuais e a rejeição à obesidade feminina fazem com que as adolescentes sintam um impulso incontrolável de estarem tão magras quanto as histórias de sucesso apresentadas pela mídia. A insatisfação com o próprio corpo pode desencadear um ciclo vicioso: sentimentos de culpa e promessas não cumpridas de começar a dieta que com práticas de comer em excesso, acabam se tornando um problema para a vida inteira.

No mundo das megeras magrelas, ou seja, o nosso, gordo comer em público é um sacrilégio. $\mathrm{Se}$ a gordinha enche o prato de salada num restaurante self-service, os outros olham penalizados e pensam: "Este balão fazendo dieta, pra quê? Imagina se uma salada vai dar jeito nesse paquiderme. Ai, ai, coitada!" Contudo, se a gordinha atreve-se a comer doces andando, por exemplo, pelos corredores de um shopping center, então o olhar de pena vem acompanhado de um desprezo já ligeiramente raivoso como se estivesse, a pobre, usando drogas injetáveis na frente de crianças. Quem passa, olha e pensa: "Que absurdo, como é que um troço desses tem coragem de continuar comendo? Por isso está desse tamanho! Não tem vergonha na cara mesmo!" Era um transtorno... (Florence, E. Hoje acordei gorda. Rio de Janeiro: Rocco, 1999).

Em função de se adequar aos padrões de beleza hoje impostos, a pessoa que tem o hábito de comer compulsivamente, se vê obrigada a manter-se sob controle.

Todos nós comemos em excesso, uma vez ou outra. Especialmente em datas especiais como Natal, aniversários... Isso não é grave quando se trata de criança ou de um homem. Mas se for uma mulher, ela começará a se preocupar com o risco de engordar, ou poderá se recriminar por não saber se controlar. Esses pensamentos logo se transformam em sentimentos de culpa. (Göckel, 1997).

A falta de controle associada ao sentimento de culpa, torna uma espiral característica do TCAP. Segundo Nunes et al. (2002),

a forma com que o paciente se alimenta pode variar muito de um paciente para o outro: ele pode ter os ataques de comer, "beliscar" durante todo o dia, fazer jejum intercalados episódios compulsivos, ter ataques de comer noturnos, etc.

Ainda segundo Nunes et al. (2002), 
o ataque de comer pode ocorrer em associação com vários transtornos tanto psiquiátricos quanto clínicos. Assim, podemos observar episódios de comer compulsivo nos transtornos alimentares (na anorexia e bulimia nervosas), mas também nos transtornos depressivos, na obesidade, na diabete, etc.

Uma característica que diferencia a compulsão alimentar da bulimia nervosa é o fato do paciente fazer o uso de dietas normalmente após o aparecimento dos ataques de comer, enquanto que na bulimia, a dieta se sucede ao uso de dietas restritivas.

Comparando pacientes com compulsão alimentar, obesos sem ataques de compulsão alimentar (obesidade hiperfágica) e os pacientes combulimianervosa, foi observado que àqueles que têm compulsão alimentar preocupam-se com a imagem corporal tanto quanto os bulímicos e evidenciou-se uma relação direta entre a obesidade e a compulsão alimentar. Para Nunes et al. (2002),

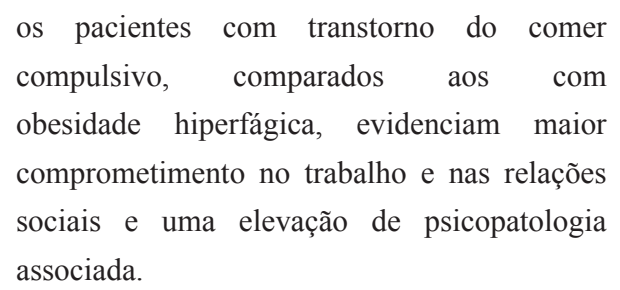

Ao avaliar um paciente obeso, é necessário verificar três campos: somático, comportamental e psicológico. Devem-se observar complicações clínicas decorrentes da obesidade: hipertensão, diabetes, etc e descartar a presença de outros transtornos alimentares. A anamnese precisa ser feita à exaustão por poder estar o transtorno do comer compulsivo associado a várias condições médicas. O comedor compulsivo tem mais tendência à depressão e freqüentemente apresenta história de outros transtornos psíquicos. Alguns pacientes relatam que a compulsão é ativada por uma variação importante do humor, como a depressão e a ansiedade. Outros não conseguem identificar o momento preciso do início dos ataques compulsivos, mas experimentam uma sensação de alívio após o período de tensão que o levou a comer.

Os sentimentos negativos, além de causarem sofrimentos, também engordam.
Tristeza, raiva e depressão são alguns sentimentos que influenciam o peso corporal, provocando a famosa "briga com a balança". É comum que as pessoas procurem no alimento uma forma de aliviar o sofrimento. A compulsão é causada pelo desejo de preencher um vazio comendo, não pela fome (Göckel, 1997).

Ir a uma churrascaria comer um rodízio e se fartar de vez em quando não é nenhum pecado. Ao contrário, pode até relaxar, depois de uma semana estressante. Mas quando o desejo de ir a um rodízio se torna freqüente, é melhor ficar alerta (Göckel, 1997).

Nas sociedades industrializadas há um forte apelo ao consumo de determinados alimentos, que são em grande parte ricos em calorias, além de inúmeros apelos à "facilidades", como entregas em domicílio, sorvetes à quilo, rodízio de massas, de carnes, de comida japonesa, de comida mineira, etc. $\mathrm{O}$ Brasil está se tornando "obeso", devido a esse modelo de alimentação americana.

O padrão de alimentação se estabelece a partir da combinação de diversos fatores (biológicos, psicológicos, socioculturais) que o favorecem e do contexto no qual o indivíduo se encontra inserido (Range, 2001). Normalmente, as pessoas

\begin{abstract}
"pressionadas por imperativos sociais, acham que é pecado deixar comida sobrando no prato, pois alguém no mundo estará deixando de ser alimentado justamente por aquele naco de carne que queremos jogar no lixo: melhor então que ele esteja em nossos estômagos em perfeita segurança e utilidade do que num lixão, tirando a subsistência de alguém. Deixando a geladeira vazia, aquela criancinha esquelética no Sudão não estará morrendo de fome por nossa causa, já que toda a comida que estava ao alcance foi aproveitada para nossa subsistência, certo? (Florence, 1999).
\end{abstract}

Agir dessa forma pode levar ao sentimento de culpa, que associado a outros fatores, podem fazer surgir os transtornos alimentares. De acordo com Rangé (2001), “a família de pacientes com Transtorno Alimentar 
dá extrema importância para a opinião dos demais". É necessário que a família esteja envolvida no tratamento dos TA, tendo os pais em função de colaboradores e facilitadores de mudanças.

\section{Possíveis Causas Intercorrentes dos Transtornos Alimentares}

Para que se entendas porque vem aumentando a incidência dos Transtornos Alimentares, é necessário conhecer um pouco da história do "Comer Mal" ou a história do "Valor da Magreza".

A partir do início do século XX, os padrões de beleza foram modificados diversas vezes. O espartilho que foi usado por quase quatro séculos desapareceu do vestuário feminino e a mulher começa então a mostrar seu corpo de outras maneiras. Nesta mesma época, surgem os figurinos de moda que coincidem com a entrada da mulher no esporte e a conseqüente moda das mulheres mais delgadas (Castro, 2001).

Com a exibição do corpo de maneira contínua e progressiva, a mulher passa a se preocupar mais com a estética corporal visível, da qual está sujeita a observações e críticas sociais. Na Renascença, valorizava-se as mulheres de corpo cheio, assim como nas décadas de 40 e 50, onde Marilyn Monroe destacava-se por seu corpo com muitas curvas, palpável mas não gorda (Castro, 2001).

No final da década de 20, com o impacto combinado das indústrias do cosmético, da moda, da publicidade e dos filmes Hollywoodianos, as mulheres passaram a usar maquiagem, se espelhando nas atrizes e passam também a valorizar o corpo esbelto, esguio. É a vitória do corpo magro sobre o corpo gordo de outrora (Castro, 2001).

Desde o início do século, moralistas burgueses e médicos foram os responsáveis pela difusão de hábitos relativos aos cuidados com o corpo e às práticas de higiene, beleza e ingresso nos esportes. O desenvolvimento do cinema e da televisão também contribuíram para a venda da imagem do corpo magro, esguio, sem formas definidas (Castro, 2001).
Os anos 60 foram marcados pela "revolução sexual", pelo movimento feminista e pelo "hippismo". O corpo é colocado em evidência como uma forma de transgressão às normas da sociedade, através das drogas e do sexo, formas de contestação que marcaram essa época. A mulher passou a ocupar postos de trabalho antes liderados somente por homens, provocando uma mudança social radical. Acredita-se então, que com a saída da mulher para o trabalho, a casa deixou de ter uma pessoa responsável pelos horários regulares de alimentação (papel tradicionalmente atribuído à mãe) e pelo desaparecimento do hábito de comer em família. Todas essas alterações nos hábitos alimentares sofreram ainda influência dos vários estilos de vida impostos pelas longas jornadas de trabalho (tanto para homens quanto para mulheres), da distância dos postos de trabalho com a residência e das dificuldades do trânsito, propiciando assim a necessidade de se comer fora de casa (Castro, 2001).

Nos anos 80, a prática de exercícios físicos passaram a ser mais regulares e cotidianas, proliferando as academias de ginástica. Cria-se a "Geração Saúde", que levantou a bandeira do "não às drogas", do "sexo seguro", fazendo exatamente o inverso à época de seus pais. Cuidar do corpo passou a ser uma necessidade, pois cuidar do corpo significa prepará-lo para ser mostrado (Castro, 2001).

A questão alimentar está certamente ligada ao tema da preocupação com a aparência física.

Em períodos de escassez, a magreza nunca foi moda. Nesses períodos, a aparência de estar bem nutrida era um sinal de que as coisas iam bem para a pessoa. E agora, em tempos de fartura, temos de ter a aparência de esfomeadas? Isso produz expectativas enormes e bem pouco realistas com relação a nossa aparência (Göckel, 1997).

O que teria levado as sociedades contemporâneas a intensificar a preocupação com o corpo e colocá-la como um dos elementos centrais na vida das pessoas? Algumas hipóteses são sugeridas: a primeira, pela facilidade para se alimentar mal, juntamente 
com a pressão social e da mídia, podem ter favorecido o aumento dos Transtornos Alimentares. Na segunda hipótese, poderíamos dizer que a cultura dos países ocidentais tem forte influência nesse processo (preocupação com dietas e magreza). Segundo Nunes et al. (2002), "os transtornos alimentares são considerados doenças dos países ocidentais desenvolvidos, considerando-se raros os casos em culturas orientais".

Todos os dias somos bombardeados com mensagens que dizem que nossos corpos não são bons o suficiente. Revistas, televisão, filmes e comerciais estão constantemente nos vendendo imagens irreais de garotas e mulheres que deveríamos imitar. A materialidade deste processo é verificada pelo crescimento das indústrias de cosméticos e produtos “diet' e "light". Devemos destacar também a importância que a mídia impressa tem nesse processo. A temática do corpo fez com que desenvolvessem ao grande número de publicações especializadas em dietas, exercícios, segredos de beleza de artistas ao qual deveríamos ter como modelos, etc. O cinema ajudou a introduzir um ideal de perfeição física, mostrando novos tipos de maquiagem, cuidados com os cabelos, técnicas para corrigir imperfeições. O mesmo pode ser pensado sobre a televisão que nos transmite imagens de corpos perfeitos, propagandas de aparelhos de ginástica com promessas milagrosas com garantia de corpos perfeitos em poucos dias, dentre outros.

Juntamente com as mensagens voltadas para o corpo, são transmitidas mensagens sobre papéis e expectativas sociais em relação às mulheres, que revelam transformações sociais importantes da identidade feminina. Talvez por isso, as estatísticas apontam que $90 \%$ das pessoas portadoras de Transtornos Alimentares são mulheres. "A insatisfação com o corpo influenciada pelo 'ideal cultural de magreza' tem levado as mulheres ao engajamento em dietas cada vez mais precocemente", diz Nunes et al. (2002).

Nem sempre a magreza extrema foi o modelo valorizado pela sociedade. Atualmente, com a imposição desse ideal de magreza e a rejeição social quanto à obesidade feminina, tem levado as adolescentes a impulsos incontroláveis de ser tão delgadas quanto às "top models" mostradas na mídia e suas respectivas histórias de sucesso (Rangé, 2001).

Com a modernização, o comportamento alimentar de homens e mulheres têm se modificado. $\mathrm{O}$ modo como os indivíduos se relacionam com a comida e o corpo passa a ser importantes metáforas na construção de suas identidades. Revelam a classe social, o sexo, a origem racial e outros hábitos construídos ao longo de suas histórias. A comida está intimamente ligada aos nossos instintos mais básicos e é essencial para nossa sobrevivência. A comida atravessa as fases mais importantes da vida de cada um de nós. É um elemento de socialização, de ligação com a família. As relações que construímos com o que comemos começam mesmo com os primeiros alimentos que ingerimos. Mais tarde, esta relação é influenciada pela forma como partilhamos estes momentos em família. Quando chegamos à adolescência, os amigos ou os grupos sociais passam a ser o mais importante da vida e a comida lá estará como forma de identidade entre nós e eles. Quando casamos e deixamos de lado as noitadas, a comida passa a ser o centro das reuniões entre amigos. Porém, é necessário que identifiquemos as sensações de fome e saciedade para que mais tarde, isso não se torne um "problema com a balança". O apetite depende de estados motivacionais e ambientais. Na motivação está envolvido um componente não menos importante que é o prazer. Segundo Kuppferman \& Schwartz (apud Nunes et al., 2002), “O prazer é um elemento inquestionável nos comportamentos motivados em humanos e em outros animais". Algumas pessoas sentem grande prazer em comer deliberadamente após a restrição de algum alimento (doces, por exemplo). O prazer é algo subjetivo e que não pode ser mensurado, porém sabemos que tem forte influência no comportamento e nos transtornos alimentares. Os transtornos do comportamento alimentar, são síndromes complexas que resultam na interação entre fatores biológicos, psicológicos e ambientais.

No cérebro, existe um centro neural responsável pelo controle da fome e da saciedade. A captação de estímulos externos 
(olfato, audição e visual) que são levados até o centro da saciedade, talvez isso explique aquela fome que sentimos subitamente diante do cheiro ou da visão de certos alimentos. Fenômenos psicológicos também interferem permanentemente com o mecanismo de fome e saciedade, porque os centros cerebrais são especialmente sensíveis aos neurotransmissores envolvidos nas sensações de prazer, raiva, amor ou medo. Por isso comemos mais quando estamos entre amigos e menos em ambientes hostis ou sob estresse psicológico (Revista Brasileira de Psiquiatria, $\mathrm{s} / \mathrm{d})$.

Muitas mulheres não conseguem mais distinguir entre fome e apetite. A fome em geral se manifesta como um ronco no estômago ou como uma contração na região do estômago, quase sempre cerca de quatro horas após a última refeição. Há mulheres que só percebem que têm fome quando ficam com dor de cabeça, começam a tremer ou se sentem mal. A fome também tem diferentes estágios. Muitas vezes o apetite ou o desejo de comer são, na verdade, fome psíquica: está nos faltando algo ou estamos em busca de algo (Göeckel, 1997).

A história da nossa espécie é marcada pela fome crônica e epidêmica. Nossos ancestrais procuravam comer alimentos muito calóricos para poder sobreviver em tempos de escassez de caça, sazonalidade de outros alimentos, etc. Durante muito tempo, o comportamento alimentar foi marcado por épocas de fartura e longos períodos de jejum forçado. Caso o centro da saciedade tivesse sido programado para desligar a fome no instante exato em que ingeríssemos a última caloria necessária para o funcionamento do organismo naquele dia, seríamos todos esbeltos. O cérebro humano foi programado então, para que em épocas de fartura, armazenasse em forma de gordura as calorias em excesso como reserva para os tempos de privação (Castro, 2001).

Somos descendentes de indivíduos onde o centro da fome só era desligado depois da ingestão de centenas de calorias em excesso. Por isso, tantas vezes levantamos da mesa com a sensação de que deveríamos têlo feito dez minutos antes. A natureza é sábia, mas não foi capaz de prever o estado de fartura atual, acessível a milhares de seres humanos (Castro, 2001).

Ao contrário dos vírus e bactérias, que podem se
adaptar a qualquer adversidade com espantosa
rapidez, o ser humano muda tão devagar que
noventa e sete por cento de nossa programação
biológica é idêntica à do tempo em que
vivíamos na idade da pedra - aquela época
em que não existiam docerias, supermercados,
lojas de conveniência, restaurantes, padarias e
quiosques nas praias. Nós não fomos equipados
para nos alimentar com nutrientes necessários
à manutenção de apenas um dia de vida. Existe
uma 'desvantagem seletiva' em comer pouco
incrustada em nossa carga genética. (Florence,
1999)

Atualmente, a questão alimentar, ou seja, os princípios de seleção que orientam o ser humano na escolha de seus recursos alimentares não são de ordem fisiológica, e sim cultural. É a cultura que cria entre os indivíduos o sistema de comunicação referente ao comestível e à saciedade. Cada vez mais, a cultura exige que deixemos de lado os doces, pães, batatas... com o objetivo de que a idéia de corpo perfeito associado ao que deveria ser a alimentação ideal, excluindo delícias que exigiriam uma dose extra de sofrimento (Morgan, 1998).

Portanto, as facilidades para se alimentar mal, juntamente com a cultura do emagrecimento, podem favorecer o aumento dos Transtornos Alimentares. E eles se tornaram mais comuns entre as mulheres, talvez porque a cultura da magreza fosse mais forte entre elas. A pressão cultural para emagrecer, associado ao nível de insatisfação com o corpo, a história da dieta e outros fatores tem nos mostrado que esses comportamentos têm se manifestado cada vez mais cedo (Morgan, 1998).

Segundo Nunes et al. (apud Brownell,1991) existem duas crenças falsas que acompanham a busca do corpo ideal:

A primeira delas é a noção de que o corpo é infinitamente maleável e que este ideal estético pode ser atingido por qualquer um que siga as prescrições culturais de exercícios e dieta adequados. Nega-se a particularidade do 
corpo de cada um e as limitações impostas pela biologia e genética. Acredita-se que a boa forma física depende apenas do esforço pessoal, crença esta corroborada pela mídia e propagandas de produtos estéticos. Além disso, a imagem do corpo ideal é acompanhada de conotações simbólicas de sucesso, autocontrole, autodisciplina, liberação sexual, classe e competência. O fracasso passa a ser equacionado com falta de força de vontade, preguiça e fraqueza. A segunda crença falsa diz respeito justamente à idéia de que aqueles que atingirem este padrão de forma corporal alcançarão tudo o que buscam, desde sucesso na profissão, nos relacionamentos sociais e até nos relacionamentos amorosos.

Ao mesmo tempo em que temos uma oferta abundante de alimentos com alto teor calórico e de rápido consumo, a vida se torna também um pouco mais sedentária. As atrizes e modelos de sucesso apresentam um corpo magro, muitas vezes com características de adolescentes, com formas pouco definidas. A busca do corpo ideal revela, na verdade, "a busca pela perfeição no contexto de uma sociedade dominada pela ênfase no narcisismo" (Nunes et al., 2002). O desempenho do indivíduo passa então a ser medido pelo seu corpo.

Com expectativas sociais novas e por vezes dúbias, o papel social da mulher foi modificado dos tempos de outrora. Mediante a este fator, Almeida (2003) descreve sobre a independência financeira, o sucesso profissional acumulados com os papéis no lar podem aumentar a insegurança e intensificar sua busca pelo controle e perfeição. Não é raro encontrarmos anoréxicas que tenham um perfeccionismo exagerado. Um dos requisitos para se ter êxito e aceitação social é ter um físico apropriado, portanto, pelos valores culturais (impostos pela mídia) é estar magra. A perda de peso, condição para se estar magra, pode realizar-se com vontade e esforço, é aqui que a jovem pode começar a ser responsável, meritosa, participativa e incrivelmente magra.

Os transtornos alimentares normalmente estão associados a transtornos psiquiátricos. $\mathrm{Na}$ anorexia nervosa, embora o transtorno depressivo seja o mais freqüente diagnóstico em associação, transtornos de ansiedade (fobia social, fobia simples e transtorno obsessivo-compulsivo) também podem ser encontrados nessa população. As pacientes com bulimia apresentam maior prevalência de abuso e dependência de álcool e drogas, automutilações, transtornos de personalidade, alterações do comportamento sexual e do controle dos impulsos (podendo ocorrer cleptomania, roubo de alimentos, tricotilomania ou suicídio). Variações de humor, depressão e ansiedade são alguns sintomas associados à compulsão alimentar e que na grande maioria das pessoas que sofrem desse distúrbio alimentar acabam por se tornarem obesas (Range, 2001)

O comportamento alimentar deveria ser regulado pelo complexo mecanismo fomesaciedade, mas é importante entender que as emoções, a ansiedade, os estados de humor depressivos e outros fatores psicológicos negativos podem alterá-lo profundamente (Nunes et al., 2002).

A intensa preocupação com a forma e o peso corporais são características comuns à anorexia e a bulimia nervosas, levando os indivíduos a recorrerem a diversas estratégias para evitar o ganho de peso. A anorexia é marcada pela perda de peso e medo irracional de engordar e busca implacável pela magreza. A bulimia é caracterizada pela ingestão compulsiva de alimentos e posterior purgação para evitar o ganho de peso. O que difere com maior clareza estas síndromes são aspectos de suas personalidades. Segundo Nunes et al. (apud Casper,1992;Bulik, 1995).

mulheres com anorexia nervosa que não apresentam sintomas bulímicos freqüentemente revelam estilos de personalidade marcados por inibição, rigidez, controle excessivo e perfeccionismo". Na bulimia nervosa, observase, predominantemente, uma incapacidade de controle de impulsos, ou seja, há uma descarga de impulsos através da ação, observada não apenas no comportamento alimentar como também em outras áreas da vida do indivíduo.

$\mathrm{Na}$ compulsão alimentar, ansiedade, tensão, tédio, perdas (de namorado, de emprego, por exemplo), planos que não dão certo e excesso de obrigações são as causas 
psicológicas da compulsão mais freqüentes. Apesar dos pacientes que têm esse transtorno não terem grandes preocupações com o peso e formato corporais, muitos dos compulsivos apresentam obesidade e fazem ou fizeram dietas (Nunes et al., 2002). Em geral, o compulsivo come sem ter fome e não se satisfaz com pouco, têm a sensação de ser "um saco sem fundo" e na maioria das vezes prefere doces.

O surgimento do transtorno alimentar, comumente é a ponta do iceberg de outros problemas psicológicos e sintomas psiquiátricos interligados que precisam ser investigados. Normalmente, portadores dos TA apresentam terror a experimentar sentimentos intensos, tanto positivos quanto negativos. Os sentimentos escondidos nos transtornos podem ser solidão, raiva, medo, rejeição, desespero. A mudança drástica na alimentação pode estar mostrando que o indivíduo está em fase de tormento psicológico, sendo incapaz de resolvê-lo de outra forma. Quanto mais a pessoa investe em seus objetivos ligados à magreza ou controle da compulsão, mais ela se desliga emocionalmente de outros relacionamentos, da família, dos amigos. Como resultado, as relações sociais ficam fragmentadas e permeadas de conflitos que envolvem comida, peso e dieta (Range, 2001).

A ansiedade é tema central da compulsão alimentar porque faz com que o comportamento desses indivíduos se torne circular. E hoje, no Brasil, temos um crescimento da população obesa, da qual grande parte tem a síndrome da compulsão alimentar. Dados estatísticos mostram que o problema chega a atingir $40 \%$ da população brasileira. (Range, 2001). No afã de querer emagrecer depressa, essas pessoas trocam uma reeducação alimentar por dietas drásticas, altamente restritivas.

A rejeição social, a pressão da mídia e em último caso a busca pela saúde mobiliza os indivíduos para emagrecerem o quanto antes. Esta busca desesperada pelo corpo magro, tem conseqüências físicas e psíquicas consideráveis. Restrições alimentares feitas por longos períodos, podem ativar ou gerar quadros ansiosos, bem como episódios depressivos. O estresse muitas vezes é reduzido via comida. Esta dieta tipo "tudo ou nada", tende a levar a um círculo vicioso: a dieta aumenta o estresse e o estresse acaba com a dieta. $\mathrm{O}$ estado depressivo, em pessoas geneticamente predispostas, provoca aumento de peso, a ansiedade aumenta a "fome psíquica" onde o alimento é utilizado para aplacar a tensão (Nunes et al., 2002).

O excesso de proibições induz a frustrações e a comportamentos de oposição e de compensação (comer demais). Está aberto o caminho para a compulsão alimentar, desencadeada por ansiedade e privação.

O alimento possui um forte componente emocional desde a infância. Quando o bebê chora porque não consegue abrir os olhos num ambiente claro, a mãe logo imagina que ele está com fome e lhe dá uma mamadeira. O bebê fica prostrado e com uma sensação corporal muito agradável diante da alimentação exagerada e passa a associar incômodos com comida. Essa relação dor/ comida é levada pela vida afora. Na verdade, o problema não é resolvido, somente é deixado em segundo plano e outrora ele reaparece. Esse círculo vicioso não tem fim porque o problema foi apenas sufocado. É interessante que se mantenha prazeres e acontecimentos bons na vida para não encontrar na comida a sensação de bem-estar necessária para a manutenção da própria vida (Morgan, 1998).

Comedores compulsivos sentem alívio provisório da sensação negativa de ansiedade, que volta reforçada pela culpa, levando a pessoa a comer mais, para tornar a diminuir a tensão. A pessoa engorda e passa a evitar toda uma gama de situações e atividades. Diminui a atividade física porque engordou, questiona sua aparência e evita ir a lugares onde tenha que se expor fisicamente. Restringe sua vida social e pode tender ao isolamento. Essa reação provoca o afastamento de outras pessoas mas o gordo parece não perceber que isto se deve ao seu comportamento e não à sua aparência. Sua ansiedade aumenta a solidão que por sua vez reforça a ansiedade. Crescendo a ansiedade, a comida que antes era um dos prazeres da vida, se torna a única fonte de prazer! (Varella, s/d) 
ConformeNunesetal. (apudAndersen et al.,1984; Garner, 1992; Silva,1995),

as pacientes com transtornos alimentares apresentam intensa ansiedade interpessoal e habilidades sociais reduzidas. Geralmente são muito autocríticas e exigentes consigo mesmas, estabelecendo metas de comportamento muito elevadas e, portanto, difíceis de atingir. Conseqüentemente, sentem-se inadequadas em seu funcionamento pessoal e social, apresentado sentimentos de baixa auto-estima. Tentam manter um comportamento "perfeito", com o objetivo de obter aprovação dos demais. Apresentam forte necessidade de controle do seu meio e ansiedade frente à possibilidade de ocorrência de mudanças, por terem medo de não serem capazes de lidar com elas.

O compulsivo alimentar percebendo que seu corpo difere daquilo que é considerado ideal, tem afetada sua auto-imagem corporal e pode engajar-se em novas dietas rigorosas, seu posterior fracasso, culpa e novo círculo vicioso. Em função da necessidade de se adequar ao padrão de beleza estabelecido para ser aceito, respeitado, acreditando que assim poderá ter uma vida melhor, mais feliz e mais saudável, entra num conflito de comer X não comer e tentam manter seus impulsos sob controle durante boa parte do dia, da semana (Göckel, 1997).

Apesar dos esforços de pesquisadores para mostrarem que dietas restritivas, sem acompanhamento médico, não fazem bem à saúde, fazer dieta tornou-se uma questão de status social, virou moda.

Segundo Rangé (apud Fairburn e Cooper, 1991; Garner, 1985; Wooley e Wooley, 1985),

Vários ganhos secundários podem ser obtidos por meio dos transtornos. Este pode ser uma “justificativa” para não ter bom desempenho escolar ou social, em que altas expectativas de desempenho estão envolvidas, ou pode ser uma justificativa para retardar a assunção de responsabilidades e a separação da família. Pode também ser uma 'rebelião passiva' de uma pessoa que não consegue rebelar-se mais diretamente contra pais superprotetores e intrusivos, em uma família na qual a alimentação tenha significado especial.

O comportamento alimentar é dificilmente modificado apenas por persuasão e informação. Exemplos são pacientes que têm acompanhamento por médicos competentes, onde têm orientação nutricional equilibrada, saborosa, são constantemente motivados e bem orientados e ainda sim acabam auto sabotando-a em algum momento, de forma irracional, demonstrando comportamento alimentar regido por emoções obscuras e não pela razão (Nunes et al., 2002).

A relação com a comida pode tornar o paciente indiferente ao ambiente de afeto que o cerca, substituindo-o por algo menos humano. Chegam a dizer que "em momentos de sofrimento, de muita dor, eles só podem contar com a comida, pois ela é a única que sempre estará lá", voltando ao estado inicial de dependência infantil da comida, que passa então a simbolizar a satisfação corporal (Nunes et al., 2002).

Os aspectos familiares presentes nos transtornos do comportamento alimentar, têm relativa importância, porque "com freqüência, os pais ignoram as atitudes patológicas de seus filhos, que são percebidas como excentricidades" (Nunes et al., 2002).

Fala-se de relações familiares conflituosas e considera-se que os pais se mostram mais próximos das filhas na primeira infância e afastadas na puberdade. Pais de pacientes com transtornos alimentares, normalmente têm um nível de exigência maior quanto ao sucesso acadêmico, social e profissional e estimulam a competição entre os filhos. Casos de depressão, excessiva rigidez, autodisciplina e distância emocional uns dos outros, alcoolismo e problemas mentais são mais freqüentes em famílias com este tipo de transtorno do que em famílias com outros tipos de transtornos. A comunicação geral e a expressão afetiva, em particular, são relatadas como restritas. Segundo terapeutas especializados, a inclusão das famílias no tratamento tem sido um recurso poderoso para pacientes com transtornos alimentares, uma vez que o foco esteja em identificar as forças e fraquezas de diferentes estilos de famílias e suas respostas quanto ao tratamento. A 
intenção é fazer uma aliança terapêutica com o paciente, fator decisivo para a boa evolução do tratamento (Range, 2001).

Para Nunes et al. (2002),

a principal característica comum a todas as famílias estudadas é a exclusividade feminina no lugar da paciente identificada. Nas estatísticas divulgadas na literatura, apenas $1 \%$ dos pacientes anoréxicos é homem. Ainda não se sabe exatamente a que atribuir essa predominância feminina, mas as hipóteses mais mencionadas referem-se às exigências sociais de beleza relacionada à esbeltez às quais se somam, neste final de século, as exigências de desempenho profissional sem perda da feminilidade. A família, como microcontexto social, reproduz essas exigências e os pais esperam das filhas que elas sejam dóceis, obedientes, dedicadas, e carinhosas dentro de casa, mas que desenvolvam, para se tornarem competitivas no mercado de trabalho, fora de casa, aspectos de asserção, liderança e autoridade, não se esquecendo de corresponder ao padrão estético vigente.

Este autor ainda registrou que

Em nossa sociedade, as mulheres são pressionadas a excluir de seu autoconceito um número significativo de qualidades pessoais e padrões de conhecimento, a fim de se considerarem femininas. $\mathrm{O}$ pensamento sexista personifica a idéia de que mulheres que tomam a iniciativa, que têm necessidade de auto-afirmação ou clamam por autoridade pessoal não são atraentes, são masculinas e agem em seu próprio benefício. Esse aspecto da opressão feminina não permite que a mulher busque os meios e a capacidade de imporse. Isso atua na arena do "corpo", até mesmo onde devem localizar-se as curvas e se devem ser excluídas (anos 60 e 70) ou exibidas (anos 80), sempre foi determinado pelos homens. Mulheres com transtorno alimentar sentem-se controladas por essas crenças, freqüentemente demonstrando receio de serem rejeitadas se derem vazão à sua parte não-feminina. Como estão constantemente reprimindo esta parte delas, sentem-se desesperadas e impotentes. A rejeição é particularmente desesperada para pacientes com transtorno alimentar, já que elas dependem dos outros para realizar funções que não podem realizar por si próprias (Nunes et al., 2002, apud Ann Kearney-Cooke, 1991).

Quando a família é convidada a participar do tratamento e esta se recusa, a paciente deve entender as limitações da mesma e modificar seu comportamento quanto às expectativas advindas dela, aprendendo a funcionar de maneira mais autônoma. Observase o crescente número de casos de transtornos alimentares na última década, motivando a criação de serviços especializados para seu atendimento, principalmente em centros universitários (Range, 2001).

Quanto aos comedores compulsivos, representam de 20 a $30 \%$ dos pacientes que procuram tratamento para emagrecer. "O comedor compulsivo tem mais tendência à depressão e freqüentemente apresenta história de outros transtornos psíquicos". (Nunes et. al., 2002). A gravidade do comer compulsivo também parece estar relacionada com o grau de obesidade. Obesos com compulsão alimentar apresentam um quadro de obesidade mais cedo do que os não compulsivos e também iniciam mais cedo a prática de fazer dietas. Normalmente, passam maior parte da vida adulta tentando perder peso. Parece conveniente, adotar um estilo de alimentação mais flexível para todos os portadores de transtornos alimentares, a fim de evitar-se o desencadeamento de episódios de compulsão alimentar (Nunes et al., 2002).

A obesidade tem se tornado um problema de saúde pública, por causa dos riscos que ela carrega, além dos custos gerados por complicações decorrentes desse estado. É preocupante o fato de que a prevalência aumenta em cada ano. Algumas complicações decorrentes da obesidade e que podem levar à morte incluem: diabete melito, hipertensão arterial, doenças coronarianas, acidente vascular cerebral, disfunções respiratórias, disfunções ortopédicas, alguns tipos de câncer (Nunes et al., 2002)

A avaliação da obesidade é feita, inicialmente, pelo registro do peso e altura do paciente para cálculo do IMC (Índice de Massa Corporal). O IMC é a razão entre o peso e ao quadrado da altura e fornece uma medida útil 
do nível de gravidade da obesidade (Range, 2001).

Em séculos passados, a gordura era exaltada, sendo o indivíduo gordo digno de confiança, pois gordura era sinônimo de força, saúde e prosperidade. Hoje, a obesidade assume um lugar diferente, o da exclusão; e os obesos se tornam passíveis de julgamentos sociais. A tolerância para a gordura diminuiu drasticamente, carregada de estereótipos depreciativos, a gordura dá lugar à magreza, que então é positivada e exaltada (Castro, 2001).

Gordos são como bexigas de aniversário: vão se inchando de desprezo, se enchendo de comentários desagradáveis, se inflando de olhares debochados, sem ruído, sem estardalhaço, até que um dia ou estouram ou murcham. Se murcham, poderão inflar de novo, obrigatoriamente inflar mais do que antes ara servir à festa e esconder a flacidez de bexiga velha. Se estouram são mal-educados, histéricos, mal amados... (Florence, 1999)

\section{Compulsão Alimentar, Obesidade e Auto- Estima}

Os transtornos alimentares são determinados por uma diversidade de fatores que interagem entre si de modo complexo, para produzir e, muitas vezes, perpetuar a doença. Há duas classes de fatores de risco para os transtornos alimentares: uma inclui o risco para transtornos psiquiátricos em geral e outra é específica para os transtornos alimentares. Dentre os fatores de risco podemos citar: transtornos psiquiátricos na família, abuso sexual ou físico, infortúnios na infância, risco para desenvolvimento da obesidade, realização de dieta calórica restritiva (Nunes et al., 2002).

Alguns traços de personalidade são característicos desses pacientes. Na anorexia nervosa é comum observarmos passividade, perfeccionismo, obsessividade. $\mathrm{Na}$ bulimia nervosa os traços de personalidade são diferentes: sociabilidade, comportamento gregário, comportamentos de risco e impulsividade. Nos pacientes com bulimia nervosa, associados à dependência química, a impulsividade e a instabilidade afetiva costumam ser aspectos centrais do temperamento desses indivíduos. A compulsão alimentar é comumente associada com transtornos do tipo evitativo e ansioso. Crianças obesas que apresentam episódios de compulsão alimentar têm maiores índices de ansiedade e depressão quando comparadas a crianças obesas sem perda de controle alimentar (Range, 2001).

$\mathrm{Na}$ puberdade, o aumento da gordura corporal em meninas, faz com que haja uma reorganização da imagem corporal e o início da preocupação com o peso e a estética corporais. A obesidade pode ter um papel deletério na auto-estima e na satisfação corporal, vulnerável às pressões culturais pela magreza.

Avaliando recém-nascidos e seus pais no que diz respeito aos fatores preditivos de problemas alimentares na infância, ficou evidente que a insatisfação corporal da mãe, a internalização do ideal de magreza, o comportamento de fazer dieta, os sintomas bulímicos e maior índice de massa corporal da mãe e do pai aumentam a chance de aparecimento de problemas alimentares na infância, o que pode aumentar o risco para transtornos alimentares no futuro.

Nunes et al. (2002) ressaltam que

O modelo cognitivo-comportamental parte do pressuposto de que o sistema de crenças de um indivíduo exerce papel determinante em seus sentimentos e comportamentos. Desta forma, os transtornos alimentares seriam mediados por pensamentos distorcidos e disfuncionais acerca de peso, alimentação e valor pessoal. Um dos esquemas de raciocínio centrais para o desenvolvimento e a manutenção dos transtornos alimentares é o que atribui valor pessoal ao peso e a forma corporais, ignorando ou não valorizando outros parâmetros. Para esses pacientes, a magreza está associada a autocontrole, competência e superioridade, tornando-se assim intrinsecamente associada à auto-estima. Outro esquema cognitivo freqüente é que a magreza é fundamental para se solucionarem os problemas da vida. As pessoas magras seriam bem-sucedidas e as gordas, infelizes e mal-sucedidas. 
A maioria dos fatores que desencadeiam a prática de comer em excesso são provenientes de natureza psicológica. Algumas razões psicológicas para comer em excesso: Raiva - os sentimentos de impotência provocam raiva, a raiva nos leva a comer, comer engorda, e ser gorda provoca sentimentos de culpa - um verdadeiro ciclo vicioso. Göckel, (1997) afirma que "normalmente a raiva está mesclada a outros sentimentos e que a depressão, muitas vezes, é a raiva que a pessoa tem de si mesma". Um dos motivos para não manifestar a própria raiva é o medo de perder o afeto dos outros, causar má impressão e "fazer um papelão". Ainda segundo essa autora, "a vergonha e os sentimentos de culpa impedem a pessoa de perceber a raiva que está sentindo. A pessoa acha que está agindo de modo errado e não se defende". Outro (bom?) motivo para comer em excesso é o medo - medo de fracassar, medo da autoridade, medo de não ser competente o suficiente, medo de não corresponder às expectativas dos outros, medo da separação, medo da perda, dentre outros medos.

\section{Para Göckel, (1997),}

o medo é um sentimento insuportável. O ser humano faz de tudo para não ter de sentir medo. Nós o "anestesiamos" com o álcool, com drogas, com comida, com sexo, com relacionamentos amorosos, com mentiras e com comportamentos ousados. Os efeitos colaterais desses "anestésicos" muitas vezes são piores que o medo que nos levou a recorrer a eles.

A função do medo é alertar-nos e proteger-nos dos perigos. É necessário que se enfrente os pequenos medos do cotidiano para desenvolver confiança e não precisar comer para "relaxar".

O terceiro motivo para comer demais é o sentimento de impotência. "Quando não encontramos saídas para as situações de desespero, isso nos conduz à resignação e a um sentimento aprendido de impotência". (Göckel, 1997).

Foi feita uma comparação entre homens e mulheres para verificar sua confiança na própria capacidade de realizar tarefas com que não estavam familiarizados. Verificou-se que os homens tinham a tendência a superestimar suas capacidades, enquanto as mulheres tinham a tendência a subestimá-las. Isto é, as mulheres se saíam muito melhor nas tarefas do que achavam que podiam. Além disso, os homens têm um outro modo de lidar com a atribuição de culpa: eles responsabilizam os outros quando algo não dá certo, enquanto as mulheres responsabilizam a si próprias e, com isso, acabam depreciando sua própria capacidade (Göckel, 1997).

A solidão também é um dos motivos para comer em excesso. Para Göckel (1997),

A solidão não tem relação alguma com viver sozinha. Podemos nos sentir muito bem sozinhas quando sabemos lidar com isso. Sem dúvida, as pessoas que vivem sozinhas de vez em quando se sentem solitárias ou entediadas, e isso pode levá-las a comer demais. Mas solidão é algo diferente. É o isolamento, o sentimento de estar excluída e não ser bem recebida. A pessoa sente que não é mais reconhecida, útil ou aceita. Todos nós passamos de vez em quando por esse tipo de experiência. Mas existe também uma solidão crônica vinculada à depressão e, em geral, ao retraimento, à baixa auto-estima e a atitudes pessimistas e autodestrutivas.

O último motivo para comer em excesso é o medo de ser magra. Como pode a magreza desejada provocar medo? $\mathrm{O}$ excesso de atenção recebida pela pessoa que deixou de ser gorda pode causar estranheza e criar estados de ansiedade por não saber lidar com essa nova situação. Declarações de pessoas que passaram por essa situação demonstram claramente quais são os medos que estão por trás da gordura: "o medo da concorrência, das exigências feitas a nós, da inveja, de ter de impor limites, de magoar alguém, de ter de tomar decisões e de defender seus direitos" (Göckel, 1997).

Uma idéia errônea é acreditar que quando estiverem suficientemente magras suas vidas "entrarão nos eixos". Acreditam que tudo será maravilhoso e perfeito sempre. Mulheres gordas, deixam de lado seus próprios desejos, interesses e necessidades, porque "em nome da paz" evitam conflitos; já que têm o "defeito" de serem gordas, sentem-se compelidas a serem simpáticas, dóceis. Ser ajustada sempre, causa desconforto por ter de abrir mão a todo instante de seus desejos. Como esse ressentimento não 
pode ser expresso, a pessoa enche a boca de comida e sorri. É um círculo vicioso sem fim (Woititz, 1989).

A comida é muitas vezes usada para preencher vazios, como apaziguamento ou mesmo como punição. Seja qual for a emoção que está na base do impulso para comer, é importante não facilitar. Doces, chocolates, guloseimas se não são boas para nós, não serão boas também para nossos filhos. Então é melhor não tê-los em casa. Devemos cultivar uma boa relação com a nossa imagem corporal. Ao fazermos isso, estamos a investir na nossa auto-estima. A forma como nos relacionamos com o nosso corpo depende da etapa da vida em que vivemos. Na adolescência, vivemos o luto pela perda do corpo infantil; na vida adulta, nos preocupamos se o organismo está funcionando bem e com o passar dos anos o que nos interessa é a saúde e a doença do nosso corpo (Göckel, 1997).

A mulher homossexual tem pouca ou nenhuma preocupação com a imagem corporal, observando que entre elas há um índice tão baixo quanto aos homens no que se refere a transtornos alimentares. Já nos homens homossexuais este índice se aproxima ao das mulheres, principalmente quando se trata de anorexia e bulimia nervosas (Ballone, s/d).

Em 1930, em seu texto “O mal-estarna civilização", Freud mostra-se intrigado acerca da valorização da beleza pela civilização, ainda que não the proporcione nenhuma utilidade. $\mathrm{O}$ autor caracteriza a fruição da beleza como uma estratégia para alcançar a felicidade. A essa fruição Freud dá o caráter de um "sentimento tenuemente intoxicante” (Freud, 1969).

De acordo com Rangé (2001),

uma das crenças centrais freqüentes é a de que a magreza é um critério fundamental de avaliação de seu valor como pessoa e que, para essas pacientes serem aceitas e respeitadas, precisam ser magras. Assim, a magreza encontra-se intrinsecamente associada à autoestima, sendo muitas vezes o único parâmetro considerado realmente importante para a autoavaliação. Acreditam também que a magreza é essencial para a obtenção de seus objetivos de vida e atribuem seus problemas ao fato de não estarem com boa aparência ou não estarem suficientemente magras (apud Fairburn, 1985; Vitousek, 1985; Freeman, 1995).

Pela falta de auto-estima, muitas mulheres obesas, denigrem-se freqüentemente, rejeitam e envergonham-se de seus corpos, sentindo-se pouco à vontade em sua intimidade. Especialistas em teorias, sugeriram que pessoas gordas que não puderam vivenciar uma relação íntima sexualmente positiva, satisfazem-se em seguida, através da comida. A combinação de excesso de gordura e hostilidade reprimida é muito destrutiva para a proximidade e bom desempenho sexual (Woititz, 1989).

Para Kaplan, (1957), comer demais pode ser: um meio de diminuir a ansiedade, insegurança, tensão, preocupação, indecisão; um meio de alcançar prazer, satisfação, sucesso; um meio de aliviar frustração, privação, desânimo; um meio de diminuir culpa, mesmo que seja a culpa por comer demais; um meio de provar inferioridade e justificar a auto-depreciação; um meio de evitar o amadurecimento emocional. Comer demais pode servir: como substituto para amor e afeto; para mostrar amor e afeto; para proteção contra os homens e matrimônio.

Woititz (1989) acredita que se você estiver obeso, você normalmente sentese sexualmente indesejável. Se você for sexualmente indesejável, você não tem que lidar com os avanços sexuais, necessários à sua maturidade sexual. A obesidade permite que você evite o problema de ter que lidar com sua sexualidade.

A obesidade torna-se dessa maneira, uma forma desadaptativa do uso do comportamento alimentar na tentativa de encobrir problemas que se tornam progressivamente insolúveis, reduzindo gradativamente as opções de vida da pessoa.

Os portadores de transtornos alimentares, tendem a apresentar "baixa autoestima, ansiedade interpessoal aumentada e dificuldades para expressar seus pensamentos e sentimentos." (Rangé, 2001). Sentem-se inadequadas e incapazes de resolver problemas da ordem social ou pessoal, dificultando assim 
sua independência. As pessoas com desordens alimentares usam a comida para se tornarem àquilo que os outros desejam que elas sejam.

É importante diminuir seu nível de exigência, fazendo-as utilizarem padrões mais realistas de avaliação. Essas pacientes tendem a valorizar apenas fracassos, desvalorizando sucessos em qualquer área, o que contribui para a manutenção dos sentimentos de insegurança e das crenças de baixa auto-eficácia, uma vez que suas conquistas são sempre insuficientes. É fundamental ajudá-las a concentrarem-se em seus sucessos e a desenvolver nelas crenças de auto-eficácia. Além disso, deve-se aumentar sua capacidade de expressão de pensamentos e sentimentos. Devem também aprender a se avaliar de modo mais multifacetado, fazendo sua auto-estima apoiar-se em outros atributos que não a aparência (Range, 2001).

Um dos fatores que levam a ingestão exagerada de alimentos é a falta de prazeres e de coisas boas acontecendo na vida. A pessoa que não tem uma fonte de prazer, encontra na comida a sensação de bem estar necessária para a sua sobrevivência. Parar de comer também não é a solução para a obesidade causada por problemas emocionais. É necessário um trabalho com uma equipe multidisciplinar, como psicólogos e nutricionistas para que haja uma investigação a fundo dos fatores que têm causado a obesidade.

\section{Considerações Finais}

Os transtornos alimentares são hoje, uma preocupação nacional, uma vez que têm aumentado consideravelmente o número de pessoas portadoras desses transtornos.

Quanto antes se der o tratamento, menos riscos para o paciente de que o prognóstico da doença caminhe para algo mais grave.

As pessoas com transtornos alimentares, por não se enquadrarem nos padrões sociais, vão se distanciando do meio social. Todos nós precisamos de aprovações de terceiros para nos sentirmos aceitos. Uma pessoa diferente dos demais, acaba por fecharse para relacionamentos e excluir-se com medo de possíveis reprovações.
O tratamento implica a participação e empenho não só do portador do transtorno alimentar. Todo o grupo familiar deve estar aberto às possíveis mudanças no estilo de vida. A equipe multidisciplinar deve trabalhar unida, fazendo fluir o tratamento.

O trabalho do psicólogo será efetivado paralelamente ao dos demais da equipe. Auxilia e serve de apoio à família. Deve focar questões emocionais que podem estar vinculadas à doença. Ao lidar com o portador de transtorno alimentar, deverá se preocupar em resgatar sua auto-estima, que na maioria das vezes, está diminuída.

\section{Bibliografia}

ALMEIDA, Cecília Maria de Melo. Trabalho de conclusão de curso. "Obesidade Infantil. AutoImagem e Auto-Estima”, 2003.

ASSOCIAÇÃO AMERICANA DE PSIQUIATRIA. Manual diagnóstico e estatístico de transtornos mentais (DSM-IV). Porto Alegre: Artes Médicas, 1995.

BALLONE, G. J. Transtornos Alimentares. Psiqweb - Psiquiatria Geral. Disponível em: $<$ http://www.gballone.sites.uol.com.br/temas/ alim_inde.html\#5. Acesso em: 05 out 2004.

CASTRO, Ana Lúcia. Sociabilidade e Estilos de vida: o culto ao corpo na cidade de São Paulo e sua relação com a mídia. 2001. 186f. Tese de Doutoramento em Ciências Sociais - Universidade de Campinas, Campinas, 2001. Disponível em: <http:// www. Efdeportes.com/ efd9/anap.htm. Acesso em: 23 set 2004.

FLORENCE, Stella. Hoje acordei gorda. Rio de Janeiro: Editora Rocco, 1999.

FREUD, Sigmund. O mal-estar na civilização. Rio de Janeiro: Imago, 1969. Vol. XXI.

GÖCKEL, Renate. Comer demais não resolve seus problemas. São Paulo: Editora Cultrix, 1997.

KAPLAN, H.; KAPLAN H. S. The psychosomatic concept of obesity. Journal of Nervous and Mental Disease, 125. 181-201. Ano 
1957. Disponível em: <http://www. geocities. com/gordinhascia/estudosanalíticos.htm. Acesso em 22 out 2004.

MORGAN, Christina M.; AZEVEDO, Angélica M. Claudino. Aspectos Sócio-Culturais dos Transtornos Alimentares. In: Oitava Conferência em Transtornos Alimentares. 1998. New York. The International Journal of Psychiatry. Psychiatry On Line Brazil. Ano 1998. vol. 3 - ${ }^{\circ}$ 02. Disponível em: <http://www.priory.com/ psych/archives.htm. Acesso em 05 de out 2004.

NUNES, Maria Angélica Antunes et al. Transtornos Alimentares e Obesidade. São Paulo: Artes Médicas, 2002.

RANGÉ, Bernard et al. Psicoterapias cognitivo-comportamentais. Um diálogo com a psiquiatria. São Paulo: Artes Médicas, 2001.

REVISTA BRASILEIRA DE PSIQUIATRIA. Etiologia dos Transtornos Alimentares; $\mathrm{n}^{\circ}$ 24, Supl. III. Disponível em: <http://www.scielo. br/pdf/rpb/v24s3/13966.pdf. Acesso em: 23 set 2004.

VARELLA, Dráuzio. Raízes Biológicas da Obesidade. Disponível em: <http://www. drauziovarella.com.br/index.asp. Acesso em 22 out 2004.

WOITITZ, J. G. Healing your sexual self. Deerfield Beach. Fl: Health Communications, Inc. Ano 1989. Disponível em: <http://www. geocities.com/gordinhascia/ estudosanalíticos. htm. Acesso em 22 out 2004.

Informações bibliográficas:

Conforme a NBR 6023:2002 da Associação Brasileira de Normas Técnicas (ABNT), este texto científico publicado em periódico eletrônico deve ser citado da seguinte forma:

MELEK, K.; MAIA, A. C. C. O.. Os Transtornos Alimentares: causas e tratamento numa visão multidisciplinar. Cadernos UniFOA, Volta Redonda, ano 3, Edição Especial, maio. 2008. Disponível em: $<$ http://www.unifoa.edu.br/pesquisa/caderno/especiais/pos-graduacao/01/21.pdf $>$ 